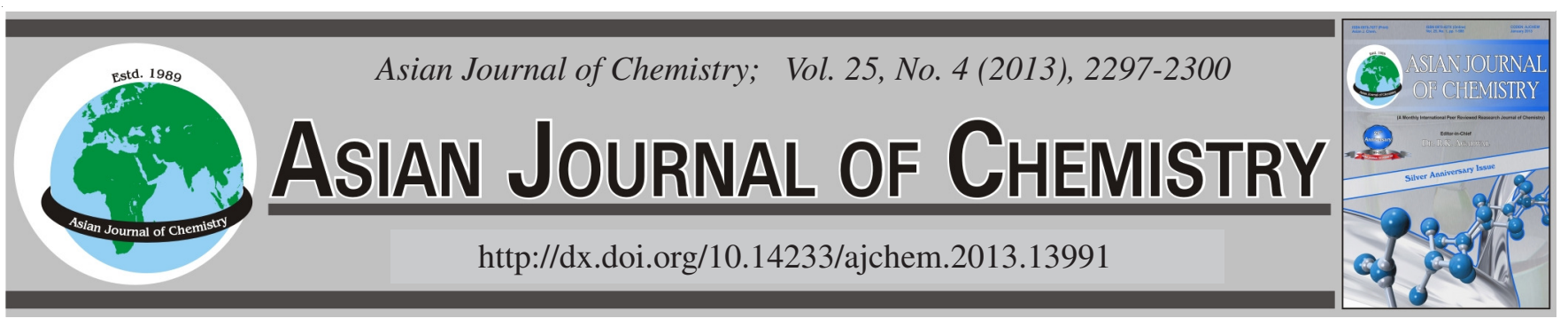

\title{
Preparation and Characterization of a Novel Porous Cation-Exchange Polymeric Monolith by Atom Transfer Radical Polymerization
}

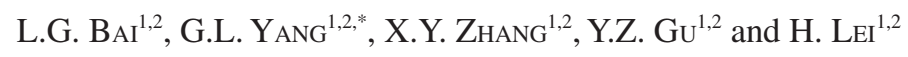

${ }^{1}$ College of Pharmaceutical Sciences of Hebei University, Baoding 071000, P.R. China

${ }^{2}$ Hebei Province Key Laboratory of Pharmaceutical Quality Control, Baoding 071002, P.R. China

*Corresponding author: Fax: +86 312 5971107; Tel: +86 312 5971108; E-mail: ygl@ @bu.edu.cn; bailigai@ 163.com

\begin{abstract}
A porous cation-exchange polymeric monolith with uniform structure has been prepared by atom transfer radical polymerization. Methyl methacrylate was used as the monomer; ferrous chloride was used as the catalyst; sodium bisulfate was first used both as inorganic moderator and co-initiator together with $\mathrm{CCl}_{4}$ to control the concentration and activity of the free radical in the process of polymerization. The characters such as morphology, pore size distribution, mechanical stability and permeability of the polymer were investigated. It revealed good chromatographic characters. The polymer was used as stationary phase of high performance liquid chromatography to separate lysozyme from chicken egg white. Besides, the mixture of Lys, papain and bovine serumal albumin had been separated by the polymeric monolith with good resolution and reproducibility.
\end{abstract}

Key Words: Atom transfer radical polymerization, Methyl methacrylate, Cation-exchange, HPLC.

\section{INTRODUCTION}

Polymers being used in chromatographic domain, such as polymeric monoliths, are often synthesized by classical in situ radical polymerization. But it has non-uniform structure by the in situ radical polymerization because of the disadvantages of slowly initiation, fast increase, easily chain transfer and quickly chain termination.

In order to avoid the disadvantages, living/control polymerization technique has been used in the preparation of chromatographic polymeric monoliths ${ }^{1-4}$. All potentially growing polymer chains grow at the same speed in living/ control polymerization technique. As a result, polymers with similar chain length are formed ${ }^{5-7}$. So a more uniform structure will be obtained.

In the present work, the porous cation-exchange polymer has been synthesized by a living/control polymerization that is atom transfer radical polymerization ${ }^{8}$. Sodium bisulfate and carbon tetrachloride were used as co-initiators and ferrous chloride as catalyst. Besides, Sodium bisulfate was also used as inorganic moderator to control the concentration and activity of the free radical in the process.

\section{EXPERIMENTAL}

Lysozyme, papain and BSA were purchased from Sigma Chemical Co. (St Louis, MO, USA). Ethylene glycol dimethacrylate was produced by Anxin Chemical Reagents Co. (Liaoning, China). Methyl methacrylate was purchased from Shanghai Chemical Reagents Co. (Shanghai, China). All of these Chemicals were analytical reagent grade. Ultrapure water was prepared from a Millipore-Q water-purification system (Taiwan, China) and all of the solutions were filtered through a $0.45 \mu \mathrm{m}$ membrane.

Preparation of the polymeric monolith: Methyl methacrylate $(0.5 \mathrm{~mL})$, ethylene glycol dimethacrylate $(0.3 \mathrm{~mL})$, $\mathrm{CCl}_{4}(0.05 \mathrm{~mL}), \mathrm{FeCl}_{2}(0.003 \mathrm{~g})$ methanol $\mathrm{A}(0.1 \mathrm{~mL})$ and dodecyl alcohol $(1.0 \mathrm{~mL})$ were added into a dry ampule. Then $0.01 \mathrm{~g} \mathrm{NaHSO}_{3}$ (solved in $0.1 \mathrm{~mL}$ of water) was poured into the ampule. The ampule was sealed with a rubber septum and degassed. Then the reaction mixture was added into the stainless chromatographic column $(50 \mathrm{~mm} \times 4.6 \mathrm{~mm}$ i.d $)$. The polymerization was allowed to proceed at $70{ }^{\circ} \mathrm{C}$ for $24 \mathrm{~h}$. At last, methanol was pumped through the monolith to wash the porogenic solvents and other soluble compounds in HPLC system (1100 system from Agilent Technologies).

\section{Characters of the polymeric monolith}

The polymeric monolith was assayed by Fourier-transfer IR (FTIR-8400S, Shimadzu Co., Japan). Morphology of the polymeric monoliths were studied by scanning electron microscopy (SEM) (KYKY 1000B, Chinese Academy of Sciences Scientific Instrument Co. Ltd., China). 

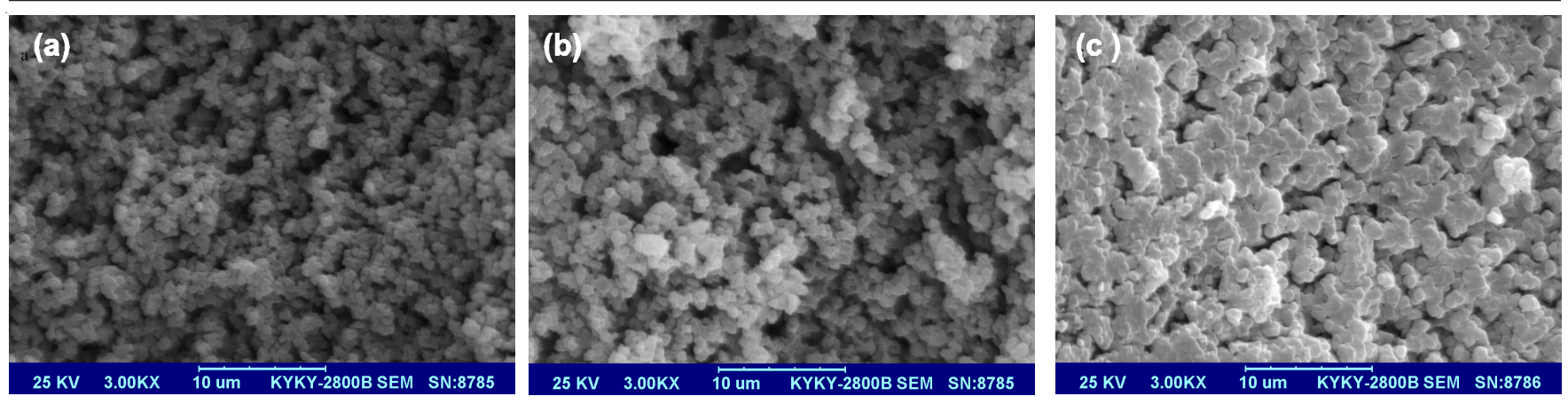

Fig. 1. Scanning electron microscopy of samples; $a$ : SEM of $M_{a}$; b: SEM of $M_{b}$; : SEM of $M_{c}$

Separation of proteins by the polymeric monolith: Lysozyme source was prepared as described previously ${ }^{9}$. The chromatographic separation was performed by using the following gradient: water for the first $3 \mathrm{~min}, 0.025 \mathrm{~mol} \mathrm{~L}^{-1}$ of $\mathrm{Na}_{2} \mathrm{HPO}_{4}$ aqueous solution $(\mathrm{pH}=10)$ for the next 3 min and $0.05 \mathrm{~mol} \mathrm{~L}^{-1}$ of $\mathrm{Na}_{2} \mathrm{HPO}_{4}$ aqueous solution $(\mathrm{pH}=10)$ for the last $3 \mathrm{~min}$.

The chromatographic conditions for the separation of the three protein mixture (lysozyme, papain and BSA) were as follow: The gradient changed linearly from $100 \% \mathrm{~A}$ to $100 \%$ $\mathrm{B}$ in $10 \mathrm{~min}$. (A was $0.05 \mathrm{~mol} \mathrm{~L}^{-1}$ of $\mathrm{NaH}_{2} \mathrm{PO}_{4}$ and $\mathrm{B}$ was 0.05 mol L-1 of $\mathrm{Na}_{2} \mathrm{HPO}_{4}$ aqueous solution.)

Determination of content of sulfonic groups on the polymeric monolith: In order to determine the content of sulfonic groups of the polymeric monolith, the following experiment has been carried out. The polymeric monolith was grinded and then about $0.1 \mathrm{~g}$ of it was weighed accurately and put into a beaker. $20 \mathrm{~mL}$ of water was added into the beaker and the beaker was put into an ultrasonator to obtain a uniform mixture. Excess $\mathrm{NaOH}\left(0.1 \mathrm{~mol} \mathrm{~L}^{-1}\right.$ aqueous solution) was added quantitatively at $25^{\circ} \mathrm{C}$. Then the excess $\mathrm{NaOH}$ solution was titrated with $\mathrm{HCl}$ aqueous solution $\left(0.1 \mathrm{~mol} \mathrm{~L}^{-1}\right)$.

Dihydroxyphthalophenone was used as the indicator. An average of three measures was the final content of sulfonic groups of the monolith.

Determination of binding capacity of the polymeric monolith for lysozyme: To determine the dynamic binding capacity of the polymeric monolith for lysozyme, frontal analysis of the column was carried out with $2 \mathrm{mg} \mathrm{mL}^{-1}$ lysozyme in the mobile phase of $0.025 \mathrm{~mol} \mathrm{~L}^{-1} \mathrm{Na}_{2} \mathrm{HPO}_{4}$ aqueous solution $(\mathrm{pH}=10)$. The binding capacity $(\mathrm{Q})$ was calculated by eqn. (1).

$$
\mathrm{Q}=\frac{\left(\mathrm{V}_{\mathrm{HB}}-\mathrm{V}_{0}\right) \mathrm{c}}{\mathrm{m}}
$$

wherein, $\mathrm{V}_{\mathrm{HB}}(\mathrm{mL})$ was the half breakthrough volume of lysozyme, $\mathrm{V}_{0}(\mathrm{~mL})$ was the dead volume of the column, $\mathrm{c}(\mathrm{mg}$ $\mathrm{mL}^{-1}$ ) was the concentration of lysozyme in the mobile phase and $\mathrm{m}(\mathrm{g})$ was the dry weight of the polymer monolith.

\section{RESULTS AND DISCUSSION}

Effect of monomer and cross-linking agent on the monolith: The effect of monomer and cross-linking agent was investigated. Compare to the previous work ${ }^{10}$, the more rate cross-linker led the smaller pore size. The optimized condition was that the volume ratio of methyl methacrylate and ethylene glycol dimethacrylate was 5:3 (v/v).
Effect of temperature on the polymerization: The preparation of polymeric monolith was thermally initiated and so temperature was a particularly effective factor. The effect of temperature could be explained in terms of the nucleation rates, at higher temperature, the polymerization reaction was very fast and more growing chains were transformed into individual globules rather than being captured by the primary nuclei. These globules were small and more small pores were produced and their surface was larger. The temperatures of $40,50,60,70$ and $80^{\circ} \mathrm{C}$ were studied, respectively. The result showed that the polymerization could not be induced when temperature were 40 and $50^{\circ} \mathrm{C}$. The polymerization could be realized when the temperature were 60,70 and $80^{\circ} \mathrm{C}$. But the polymer had bad mechanical function when the temperature was $60{ }^{\circ} \mathrm{C}$ and had high backpressure when the temperature was $80^{\circ} \mathrm{C}$. When the temperature was $70^{\circ} \mathrm{C}$, the polymer had good mechanical function and good permeability. So, $70{ }^{\circ} \mathrm{C}$ was chosen as the temperature of polymerization.

Effect of porogen on the polymerization: Dodecyl alcohol and isopropyl alcohol were investigated as porogens, respectively. The polymeric monolith prepared with isopropyl alcohol being used as the porogen had much higher backpressure and worse permeability than that of dodecyl alcohol. The reason was that dodecyl alcohol was a poorer solvent than isopropyl alcohol. In the process of pore-forming, larger pores would be obtained with a poor solvent due to an earlier onset of phase separation.

SEM figures of the polymeric monoliths: The morphologies of the polymeric monoliths were investigated by SEM and the results were shown in Fig. 1. The figures showed that $\mathrm{M}_{\mathrm{a}}$ had a more uniform structure than $\mathrm{M}_{\mathrm{b}}$. $\mathrm{M}_{\mathrm{c}}$ had smaller pore size than that of $\mathrm{M}_{\mathrm{a}}$ and $\mathrm{M}_{\mathrm{b}}$. The pore diameter of $\mathrm{M}_{\mathrm{a}}$ was about $1 \mu \mathrm{m}$ that was large enough for the separation of macromolecules.

Mechanical stability and permeability of $\mathbf{M}_{\mathbf{a}}$ : To determine the mechanical stability and permeability of the monolith, the back-pressure drop at several flow rates were investigated. Fig. 2 showed the effect of the flow rate on the back pressure of $\mathrm{M}_{\mathrm{a}}$ with water (b) and methanol (a) as the mobile phases, respectively. Good linear relations had been obtained $\left(\mathrm{r}_{\mathrm{a}}=\right.$ $\left.0.9991, r_{b}=0.9990\right)$. These results clearly indicated that the internal structures of the monoliths were not damaged and were suitable for high-throughput elution.

Pore size distribution: The pore size distribution of $\mathrm{M}_{\mathrm{a}}$ was characterized by mercury intrusion porosimetry and the result was shown in Fig. 3. The result indicated that the general 


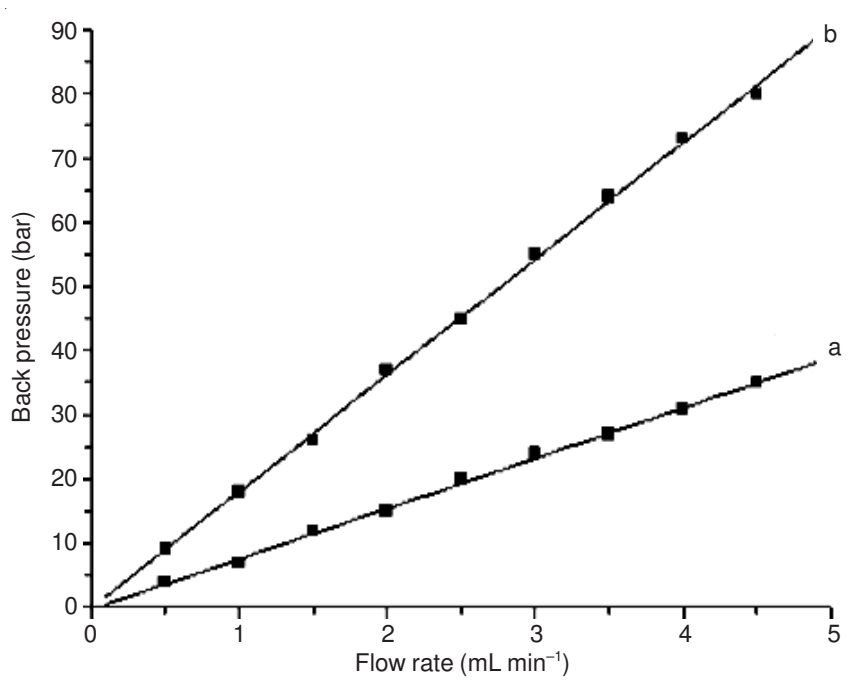

Fig. 2. Back-pressures of the polymeric monolith at different flow rates; a:methanol was used as the mobile phase; $b$ : water was used as the mobile phase

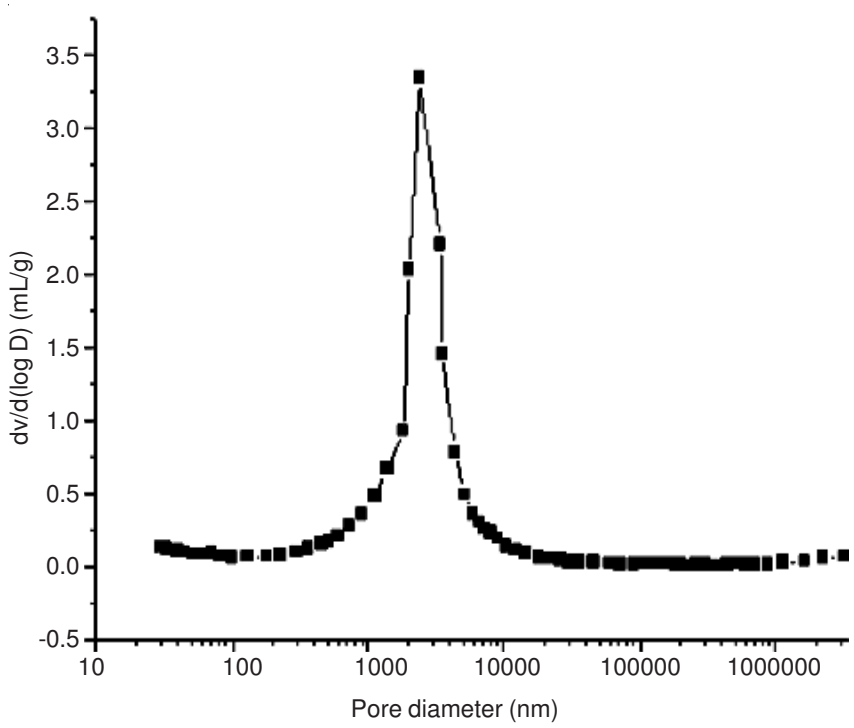

Fig. 3. Pore size distribution profiles for the monolith (Ma) by mercury intrusion porosimetry

pore volume, average pore diameter and internal porosity were $1.25 \mathrm{~mL} \mathrm{~g}^{-1}, 1.09 \mu \mathrm{m}$ and $64.74 \%$, respectively.

IR spectra of $\mathbf{M}_{\mathrm{a}}$ : The IR spectra of monolith were shown in Fig. 4. The absorption at $2990 \mathrm{~cm}^{-1}$ and $2950 \mathrm{~cm}^{-1} \mathrm{C}-\mathrm{H}$ were due to the stretching in $\mathrm{C}-\mathrm{H}$ of an aromatic group or alkenes. The clear adsorption peak at $1725 \mathrm{~cm}^{-1}$ was due to $\mathrm{C}=\mathrm{O}$; the peak at $1480 \mathrm{~cm}^{-1}$ showed the presence of the $\mathrm{C}-\mathrm{O}-\mathrm{C}$ group. The absorptions observed at $1250 \mathrm{~cm}^{-1}$ and $1150 \mathrm{~cm}^{-1}$ were caused by $-\mathrm{HSO}_{3}$. This indicated that the cation exchanger $\left(-\mathrm{HSO}_{3}\right)$ had been connected onto the monolith successfully.

Content of sulfonic group of $\mathbf{M}_{\mathbf{a}}$ : The content of sulfonic group was $0.29 \mathrm{mmol} \mathrm{g}^{-1}$ that was calculated by eqn. (2).

$$
\mathrm{x}=\frac{\left(\mathrm{V}_{0}-\mathrm{V}_{1}\right) \mathrm{C}}{1000 \mathrm{~W}}
$$

where, $\mathrm{V}_{0}$ : the volume of $\mathrm{NaOH}$ solution $(\mathrm{mL}) ; \mathrm{V}_{1}$ : he volume of $\mathrm{HCl}$ solution $(\mathrm{mL})$; $\mathrm{C}$ : the concentration of standard solution $\left(\mathrm{mol} \mathrm{L}^{-1}\right) ; \mathrm{W}$ : the quality of sample $(\mathrm{g})$.

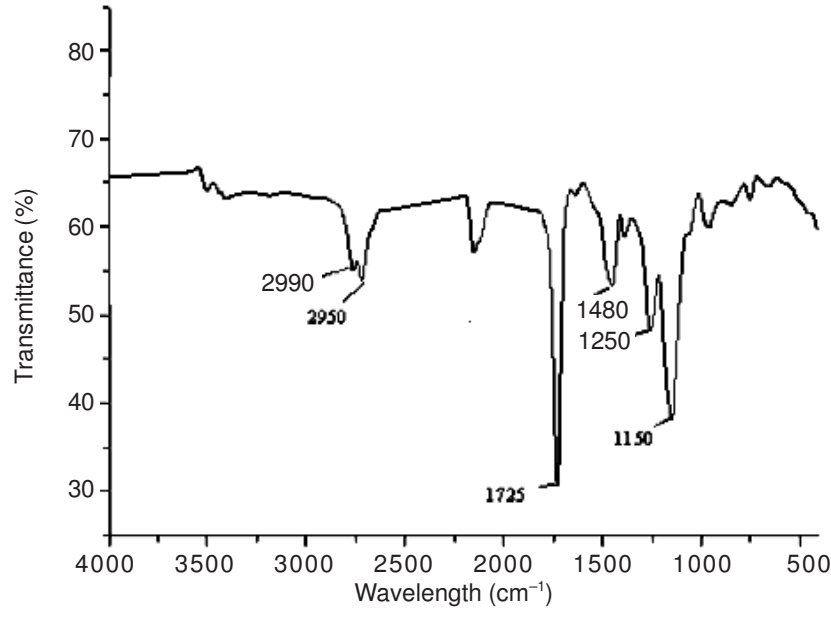

Fig. 4. FT-IR spectra of $M_{a}$

Chromatographic characters of the polymeric monoliths: Fig. 5 (a, b and c) showed the separations of lysozyme from chicken egg by $M_{a}, M_{b}$ and $M_{c}$, respectively. There were three distinct peaks in (a) and the second one was due to lysozyme. There was only one peak in (b) that suggested $\mathrm{M}_{\mathrm{b}}$ had no ability to separate lysozyme from chicken egg white. The reasons were that $\mathrm{M}_{\mathrm{a}}$ and $\mathrm{M}_{\mathrm{c}}$ had negatively charged sulfonic groups that were cation exchangers. When $\mathrm{pH}$ of mobile phase was lower than the pI of lysozyme (about 11), lysozyme was positive charged. Then there would be cationexchange between lysozyme and polymeric monolith. So lysozyme would be remained by the polymeric monolith in the first 3 min when water was used as the mobile phase. When the $\mathrm{pH}$ of mobile phase was near to 11 , there was seldom positive charge in lysozyme and then lysozyme was eluted from the polymeric monolith in the next 3 min when $\mathrm{Na}_{2} \mathrm{HPO}_{4}$ aqueous solution $\left(0.025 \mathrm{~mol} \mathrm{~L}^{-1}, \mathrm{pH}=10\right)$ was used as the mobile phase.

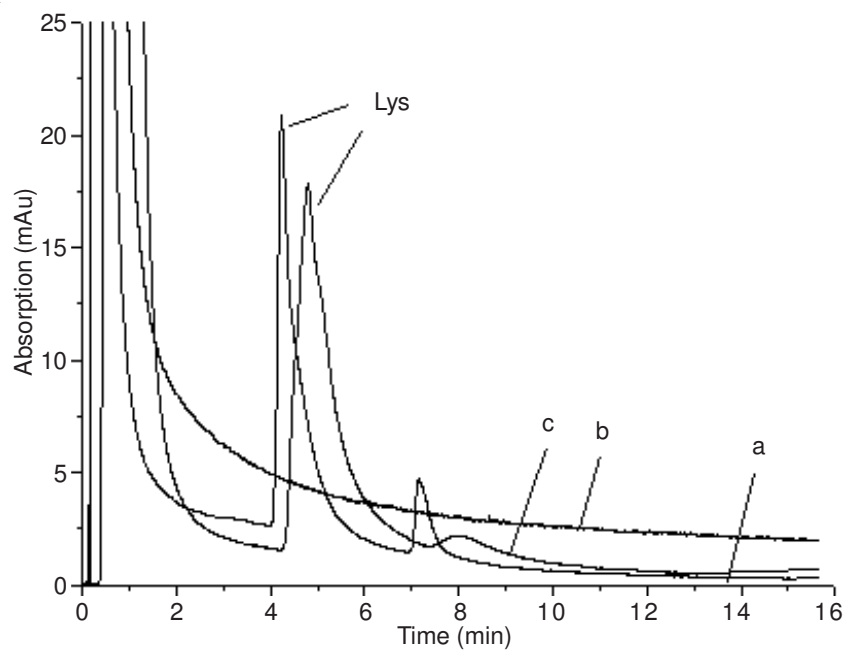

Fig. 5. Separation of lysozyme from chicken egg white; a: Chromatogram by the $\mathrm{M}_{\mathrm{a}}$; $\mathrm{B}$ : Chromatogram by the $\mathrm{M}_{\mathrm{b}}$; $\mathrm{c}$ : Chromatogram by the $\mathrm{M}_{\mathrm{c}}$; Chromatographic conditions: the prepared polymeric monoliths, $50 \mathrm{~mm} \times 4.6 \mathrm{~mm}$ i.d., respectively; injection volume: $3.0 \mu \mathrm{L}$; flow rate: $1.0 \mathrm{~mL} \mathrm{~min}^{-1}$; the gradient: water for the first $3 \mathrm{~min}, 0.025 \mathrm{~mol}$ $\mathrm{L}^{-1}$ of $\mathrm{Na}_{2} \mathrm{HPO}_{4}$ aqueous solution $(\mathrm{pH}=10)$ for the next $3 \mathrm{~min}$ and $0.05 \mathrm{~mol} \mathrm{~L}^{-1}$ of $\mathrm{Na}_{2} \mathrm{HPO}_{4}$ aqueous solution $(\mathrm{pH}=10)$ for the last $3 \mathrm{~min}$ 
There were three peaks in (c), but the efficiency and resolution of monolith were low. The results suggested that proper pore size and uniform structure were important chromatographic characters that affected the separation directly.

$\mathrm{M}_{\mathrm{a}}$ revealed good stability in separating lysozyme from chicken egg white. Under the given conditions, the RSD of retention time and peak area was $0.20 \%(\mathrm{n}=11)$ and $0.98 \%$ $(\mathrm{n}=11)$, respectively.

Dynamic binding capacity of $\mathbf{M}_{\mathbf{a}}$ for lysozyme: According to the process being described in section 2.3.5, the binding capacity of $\mathrm{M}_{\mathrm{a}}$ for lysozyme was $3.53 \mathrm{mg} \mathrm{g}^{-1}$.

\section{Conclusion}

A novel porous cation-exchange polymeric monolith with uniform structure has been polymerized by atom transfer radical polymerization. Sodium bisulfate was first used both as co-initiator to provide sulfonic group and inorganic moderator to control the concentration and activity of the free radicals, respectively. The polymeric monolith had high permeability and low back pressure. Moreover, the monolith was used as HPLC stationary phase to separate the mixture of lysozyme, papain and BSA successfully. Moreover, lysozyme has been separated successfully from chicken egg white by the polymeric monolith The results suggested that this kind of polymeric monolith could be used as an effective HPLC stationary phase to separate certain proteins.

\section{ACKNOWLEDGEMENTS}

The authors are grateful for financial support by the National Natural Science Foundation of China (No. 21175031); the Applied Basic Research Program Key Basic Research Project of Hebei Province (No. 11966411D); the 12th Five-Year Plan of Significant New Drug Major Science and Technology of Ministry of Science and Technology of China (No. 2012ZX09103-101057); the Key Project of Science and Technology of Research of College of Department of Education of Hebei Province (No. ZD2010234).

\section{REFERENCES}

1. R.Y. Zhang, Q. Li, P.Y. Xin, G.L. Yang and Y. Chen, Polymer, 51, 1703 (2010).

2. L.G. Bai, H.Y. Liu and Y.K. Liu, X.H. Zhang, G.L. Yang and Z.Y. Ma, J. Chromatogr. A, 1218, 100 (2011).

3. P. McCarthy, M. Chattopadhyay, G.L. Millhauser, N.V. Tsarevsky, L. Bombalski, K. Matyjaszewski, D. Shimmin, N. Avdalovic and C. Pohl, Anal. Biochem., 366, 1 (2007).

4. H. Wang, X. Dong and M. Yang, TrAC Trend. Anal. Chem., 31, 96 (2012).

5. M. Kato, M. Kamigaito, M. Sawamoto and T. Higashimura, Macromolecules, 28, 1721 (1995).

6. D.Q. Qin, S.H. Qin, X.P. Chen and K.-Y. Qiu, Polymer, 20, 7347 (2000).

7. Z.P. Cheng, X.L. Zhu, N.C. Zhou, J. Zhu and Z.B. Zhang, Radiat. Phys.Chem., 72, 695 (2005).

8. J.S. Wang and K. Matyjaszewski, J. Am. Chem. Soc., 117, 5614 (1995).

9. M. Yilmaz, G. Bayramoglu and M.Y. Arica, Food Chem., 84, 591 (2004).

10. F. Svec, J. Chromatogr. A, 1217, 902 (2010). 